\title{
Sistem Informasi Key Performance Indicator Penjualan Metode OMAX berbasis Web System Application
}

\author{
Giandari Maulani*1, Kharisma Nur Qhoirunnisa ${ }^{2}$, Tri Mulyani ${ }^{3}$ \\ 1, 2, 3 Program Studi Sistem Informasi Universitas Raharja \\ Email: *11 giandari@ raharja.info, ${ }^{2}$ kharisma@ @raharja.info, ${ }^{3}$ tri.mulyani@ raharja.info
}

\begin{abstract}
Abstrak
PT. Winn Appliance sebuah perusahaan yang bergerak dalam bidang penjualan komoditi rumah tangga yakni alat-alat gas. Saat ini dalam melaksanakan pelaporan data penjualan sales PT. Winn Appliance masih menggunakan Microsoft Excel dan media Whatsapp sebagai sarana media dalam memberikan informasi serta laporan dari hasil penjualan yang nantinya merupakan indikator bagi manajemen perusahaan dalam menentukan keputusan perpanjangan kontrak kerja. Tujuan dari perusahaan perlu dicapai melalui sebuah target yang telah ditetapkan untuk setiap sales penjualan, sekaligus mengukur prestasi pencapaian target tersebut. Maka pengukuran tersebut dapat menggunakan Key Performance Indicator yang berintregrasi satu sama lain. Untuk itu dibentuklah sebuah sistem informasi Key Performance Indicator Penjualan berbasis Web System Application. Kemudian dalam menentukan perancangannya membutuhkan sebuah metode yang tepat dan metode yang diterapkan dalam penelitian ini yakni menggunakan metode OMAX (Objective Matrix). Bahasa pemrogramannya menggunakan PHP Framework Code Igniter dan MySql sebagai pengatur penyimpanan basis data yang dapat menunjukkan nilai target Performance Indicator Penjualan yang telah dicapai. Hasil dari penelitian ini merupakan Sistem Informasi Key Performance Indicator Penjualan metode OMAX berbasis Web System Application yang dapat mempermudah manajemen PT. Winn Appliance dalam melakukan Monitoring penjualan dan berguna untuk menentukan keputusan kontrak kerja.
\end{abstract}

Kata Kunci: Sistem Informasi, Key Performance Indicator, Metode OMAX, Web System Application.

\begin{abstract}
PT. Winn Appliance is a company engaged in the sale of household commodities, namely gas appliances. Currently in carrying out sales data reporting sales PT. Winn Appliance still uses Microsoft Excel and Whatsapp media as a medium for providing information and reports on sales results which will later serve as indicators for company management in determining the decision to extend the work contract. The goals of the company need to be achieved through a predetermined target for each sales, as well as measuring the achievement of these targets. Then these measurements can use a Key Performance Indicator which integrates with each other. For this reason, a Web System Application-based Key Performance Indicator information system was established. Then in determining the design requires an appropriate method and the method applied in this research is using the OMAX (Objective Matrix) method. The programming language uses the PHP Framework Code Igniter and MySql as a database storage regulator that can show the Sales Performance Indicator target value that has been achieved. The result of this research is Information System Key Performance Indicator Sales of OMAX method based on Web System Application which can facilitate the management of PT. Winn Appliance in monitoring sales and is useful for determining employment contract decisions.
\end{abstract}

Keywords: Information Systems, Key Performance Indicators, OMAX Method, Web System Application. 


\section{Pendahuluan}

Terbentuknya satu organisasi ataupun perusahaan didasarkan dengan sebuah visi dan tujuan yang harus dicapai oleh organisasi ataupun perusahaan tersebut. Dilakukan dengan berbagai macam cara untuk mencapai tujuan agar nantinya setiap kinerja organisasi dan perusahaan tersebut terus meningkat berkembang. Salah satu faktor yang dapat mengukur satu peningkatan kinerja penjualan untuk mencapai hasil dan tujuan suatu perusahaan adalah dalam hal pengelolaan kinerja kerja yang efektif dan maksimal. Key PerformanceIndicator adalah satuan dari rumusan metrik keuangan ataupun non-keuangan yang kerap digunakan oleh setiap perusahaan dalam membantu menentukan dan mengukur kemajuan terhadap sasaran perusahaan (Parmenter, 2014).[1] Sistem Informasi yang tepat sangat berperan penting dalam sebuah proses bidang bisnis ataupun operasionalnya manajemen perusahaan tersebut. Maka dengan berkembangnya sistem informasi dan teknologinya, penggunaan komputer tidak hanya sebagai pengolah data saja, tetapi komputer juga dapat menjadi sebuah media informasi yang dapat diakses setiap saat (Junaidi, Et Al, 2018).[2] Relevansi dan pentingnya informasi dapat membantu kinerja kerja dimana hal ini tidak terlepas dari berbagai perkembangan dan kemajuan yang dicapai di bidang ilmu pengetahuan dan teknologi (IPTEK). Dampak dari berbagai kemajuan tersebut dapat bersifat positif dan juga bisa negatif (Cholisoh, $\mathrm{N}$ et al, 2019).[3] Dalam upaya untuk mengatasi sebuah permasalahan-permasalahan yang ada, maka perlu dikembangkan sistem yang berintregrasi terdiri dari proses pengukuran hasil kinerja yang secara objektif melalui alur sistem indikator kinerja yang sempurna. Dirancangnya sistem informasi Key Performance Indicators (KPI) yang berbasis Web System Aplication, diharapkan nantinya manajemen dan marketing sales dapat meningkatkan sebuah angka penjualan secara optimal serta objektif sehingga memberikan kontribusi positif bagi setiap karyawan dalam suatu perusahaan yang dapat digunakan sebagai sistem yang menentukan keputusan perpanjangan kontrak kerja.

\section{Metode Penelitian}

Objective Matrix (OMAX) merupakan Suatu sistem pengukuran produktivitas parsial yang dikembangkan untuk memantau produktivitas di setiap bagian perusahaan dengan kriteria produktivitas yang sesuai dengan keberadaan bagian tersebut objektif (Sari Retno PA, et all 2018).[4] Perusahaan dapat melakukan pengukuran produktivitas penjualan secara parsial dan sistemis yang nantinya dikembangkan dalam satu aplikasi berbasis website untuk menentukan keputusan perpanjangan kontrak kerja. Untuk mengetahui sebuah nilai produktivitas penjualan sendiri dapat menggunakan rumus:

\section{Rasio 1}

total produk yang terjual $\times 100 \%$ jumlah jam kerja sales yang tersedia

$$
\frac{918}{177}=5.1864
$$

Contoh periode Desember 2018 s/d Maret 2019

\section{Rasio 2}

total produk yang gagal terjual $\times 100 \%$ yang didistribusi 


\section{$\frac{10}{177} \times 100 \%=0,108$}

Contoh periode Desember 2018 s/d Maret 2019

Tabel 1. Tabel Rasio Produktifitas Penjualan

\begin{tabular}{|c|c|c|}
\hline \multirow{2}{*}{ Kreteria } & Rasio 1 & Rasio 2 \\
\cline { 2 - 3 } B bulan & operator) & \\
\hline Desember & 5.1864 & 0.0108 \\
\hline Januari & 5.1952 & 0.0320 \\
\hline Febuari & 4.8465 & 0.0105 \\
\hline Maret & 5.3181 & 0.0117 \\
\hline Rasio & 5.1083 & 0.0192 \\
rata-rata & & \\
\hline Rasio terbaik & 5.3181 & 0.0320 \\
\hline Rasio & & \\
terburuk & 4.8465 & 0.0105 \\
\hline
\end{tabular}

Dari tabel di atas dapat di lihat hasil produktivitas terbaik terdapat pada bulan Maret 2018 dengan nilai rasio 1 adalah 5.3181 dan produktivitas terendah terdapat pada bulan Febuari 2018 dengan nilai rasio 1 adalah 4.8465 hal ini dapat di lihat dari rasio 1 , sedangkan rata - rata pada nilai produktivitas di atas adalah 5.1083 .

Di tahapan selanjutnya dalam penelitian ini dianalisa menggunakan SDLC (System Development Life Cycle) dengan bentuk Waterfall. Menurut Satzinger, et al (2015:42) dalam SZ Friandi, et all (2019), metode SDLC dengan model tipe Waterfall atau biasa disebut model klasik ini bersifat sistematis, prosedur teratur, serta akurat dalam merancancang dan membangun sebuah karya sistem aplikasi. Model waterfall ini juga biasa disebut dengan istilah sekuensial linier.[5] 


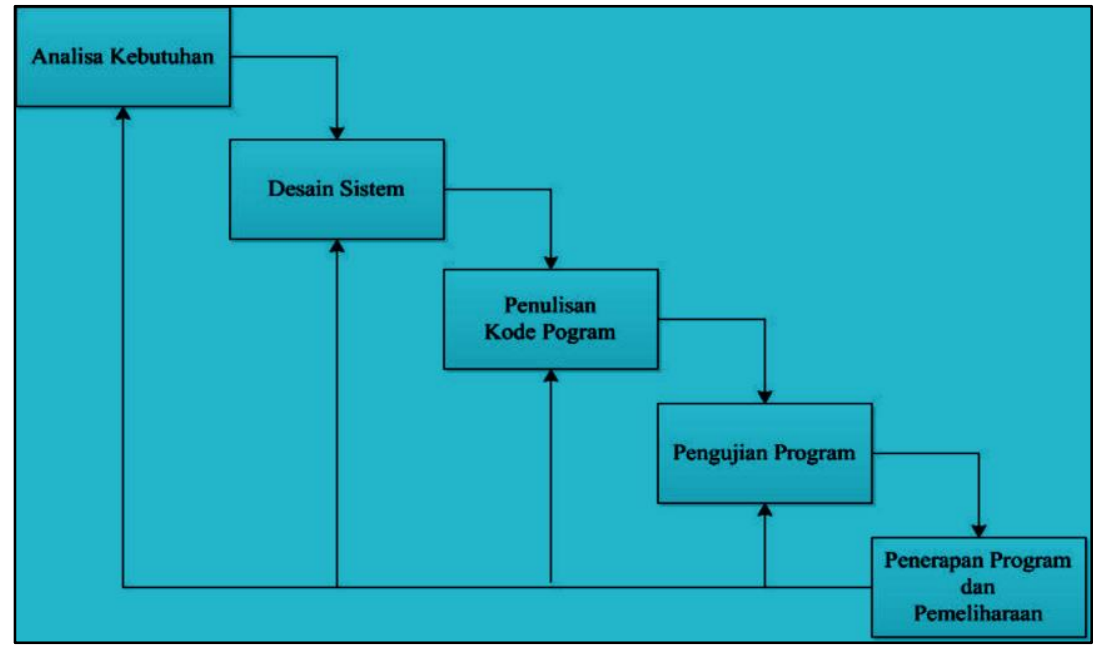

Gambar 1. Alur tahapan SDLC (System Development Life Cycle)

Tahapan SDLC (System Development Life Cycle) Model Waterfall sebagai berikut :

1. Analisa Kebutuhan

Langkah ini merupakan tahapan dalam mencari suatu kebutuhan yang nantinya dikembangkan ke dalam sistem.

2. Desain Sistem

Tahapan dimana dilakukan penuangan pikiran terhadap perancangan alur sistem yang menjadi solusi dari permasalahan, dengan menggunakan perangkat pemodelan seperti diagram Usecase, Activity, Sequence dan Class diagram.

3. Penulisan Rumus Kode Program

Penulisan kode program (coding) merupakan penerjemahan design dalam bahasa pemrograman komputer. Dilakukan oleh programmer yang akan meterjemahkan transaksi data yang diinginkan oleh Stakeholder.

4. Pengujian Program

Tahapan sistem yang baru diuji kemampuan dan keefektifannya sehingga akan ditemukan kekurangan dan kelemahan yang kemudian nantinya akan dilakukan pengkajian ulang dan perbaikan terhadap aplikasi menjadi lebih baik dan sempurna sehingga dapat diimplementasikan.

5. Implementasi Program dan Pemeliharaan

Program yang sudah selesai dibuat disampaikan serta diimplementasi pada perusahaan nantinya mengalami perubahan dan pengembangan. Perubahan tersebut bisa jadi karena Stakeholder membutuhkan perkembangan fungsional.

\section{Landasan Teori Penelitian}

\section{UML (Unified Modeling Language)}

UML (Unified Modeling Language) Menurut Wandanaya, A.B. et all (2019) adalah Suatu bahasa pemodelan untuk menggambarkan alur prosedur sistem dan perangkat lunak yang berorientasi objek.[6] 


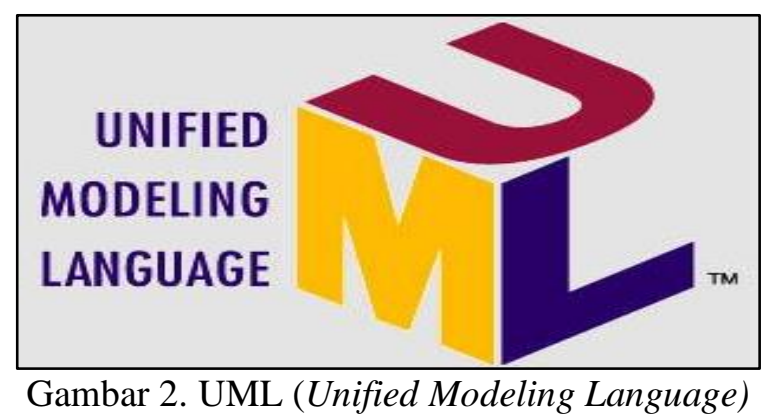

\section{Website}

Website adalah Sekumpulan halaman data dan informasi yang disediakan melalui jalur internet sehingga bisa dan mudah diakses dimanapun selama perangkat media masih terkoneksi dengan jaringan internet. Website merupakan sebuah komponen yang terdiri dari teks, gambar, suara, animasi sehingga menjadi media data dan informasi yang menarik untuk dikunjungi oleh setiap orang, maka bisa kita pahami bahwa definisi website secara sederhana adalah "sumber data dan informasi yang bisa diakses dengan menggunakan koneksi jaringan internet". (Gregorius, 2000).[7]

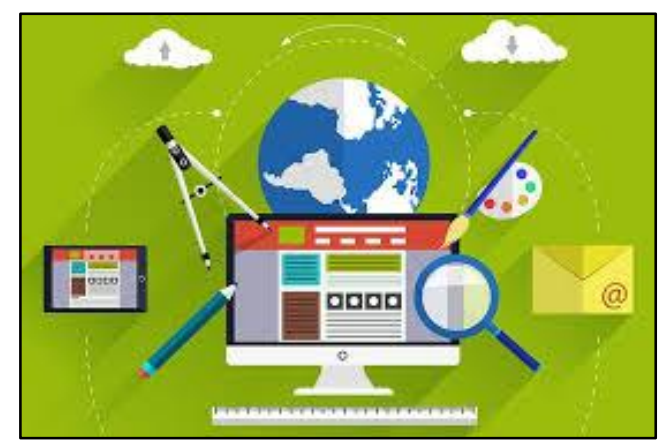

Gambar 3. Website

\section{Yii Framework}

Yii adalah kerangka kerja (Framework) open source berbasis php. Nama Yii (dieja sebagai /i:/) singkatan dari "Yes It Is!".Seperti juga Framewor PHP pada umumnya, Yii juga telah mengadopsi konsep MVC - Model, View, Controller dalam struktur pemogramanya.Proyek pengembangan Yii dimulai sejak 1 Januari 2008 oleh Qiang Xue programer asal Tiongkok. Pada awalnya Yii dikembangkan menggunakan bahasa kerja PRADO framework, setelah mengalami beberapa koreksi dan penyempurnaan kurang lebih setahun, pada 3 Desember 2008, Yii 1.0 secara resmi dirilis ke publik. (Rifai, 2018).[8]

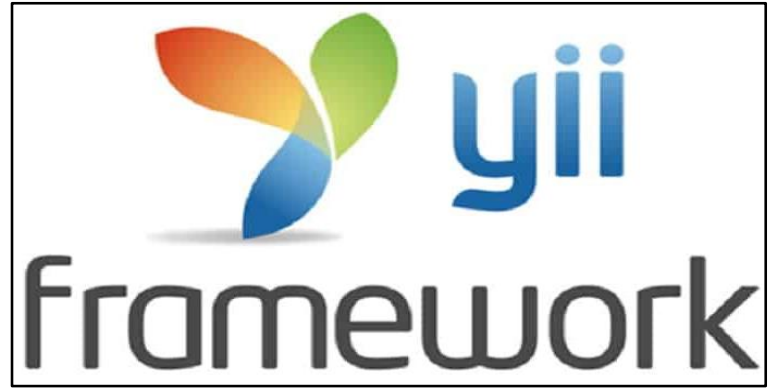

Gambar 4. Yii Framework 


\section{Kerangka Pemikiran}

Dalam satu penelitian penulis akan mencoba membuat konsep kerangka pemikiran untuk memberikan gambaran mengenai pokok pembahasan pada penelitian secara skematis kerangka pemikiran penelitian sebagai berikut :

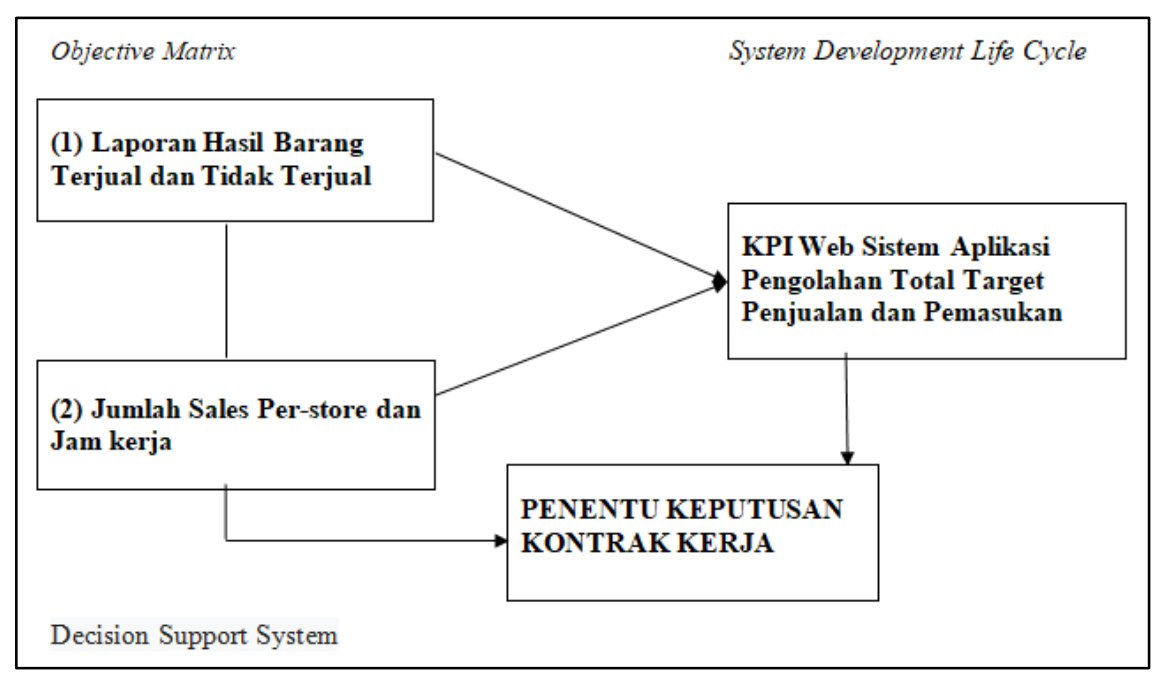

Gambar 5. Skema Kerangka Pemikiran

Alur Skema Kerangka Pemikiran diatas:

1. OMAX (Objective Matrix) $1 \rightarrow$ System Development Life Cycle: di proses secara sistematis dalam sebuah web aplikasi KPI

2. OMAX (Objective Matrix) $2 \rightarrow$ System Development Life Cycle : di proses secara sistematis dalam sebuah web aplikasi KPI

3. OMAX (Objective Matrix) 1 dan OMAX (Objective Matrix) $2 \rightarrow$ System Development Life Cycle $\rightarrow$ Decision Support System : Dalam pemrosesan data laporan penjualan sales dalam sebuah sistem Web aplikasi Key Performance Indicator (KPI) maka nantinya manajemen dapat menghasilkan satu penentu keputusan perpanjangan kontrak kerja.

\section{Perumusan Masalah}

Setelah peneliti melakukan tahapan identifikasi permasalahan, maka peneliti mendapatkan rangkuman permasalahan yang nantinya dipecahkan dalam penelitian ini. yaitu : Sistem seperti apa yang berjalan dalam memonitoring penjualan dalam menentukan keputusan kontrak kerja? Selanjutnya bagaimana cara merancangan Web Application System KPI yang nantinya dapat menjadi solusi untuk memonitoring penjualan dan menentukan keputusan perpanjangan kontrak kerja pada PT. Winn Appliance? Perumusan masalah-masalah ini akan dijawab dengan lengkap pada kesimpulan di penelitian ini.

\section{Hasil Dan Pembahasan}

\section{Pemecahan Masalah}

Setelah proses analisa sistem yang sedang berjalan pada PT. Winn Appliance, maka dilanjutkan pada tahap proses selanjutnya yaitu mengenai sebuah rancangan sistem yang akan dibangun. Ada beberapa usulan prosedur yang bertujuan untuk memperbaiki dan memperbarui 
sistem saat ini, Yaitu mengubah proses penginputan yang saat ini masih MS-Excel menjadi satu program yang tersistematis dan komputerisasi berbasis Web Aplikasi sehingga memudahkan bagian manajemen untuk mengontrol data penjualan dan performa sales.

Saat semua kebutuhan sistem telah diputuskan dan ditentukan, maka tahap selanjutnya yaitu desain sistem usulan yang bertujuan merubah sistem yang lawas dengan memberi gambaran visual atau pandangan jelas menurut proses desain awal sampai finishing. Berikut merupakan prosedur sistem baru yang divisualisasikan melalui software Visual Paradigm 6.0 dalam bentuk Use case Diagram :

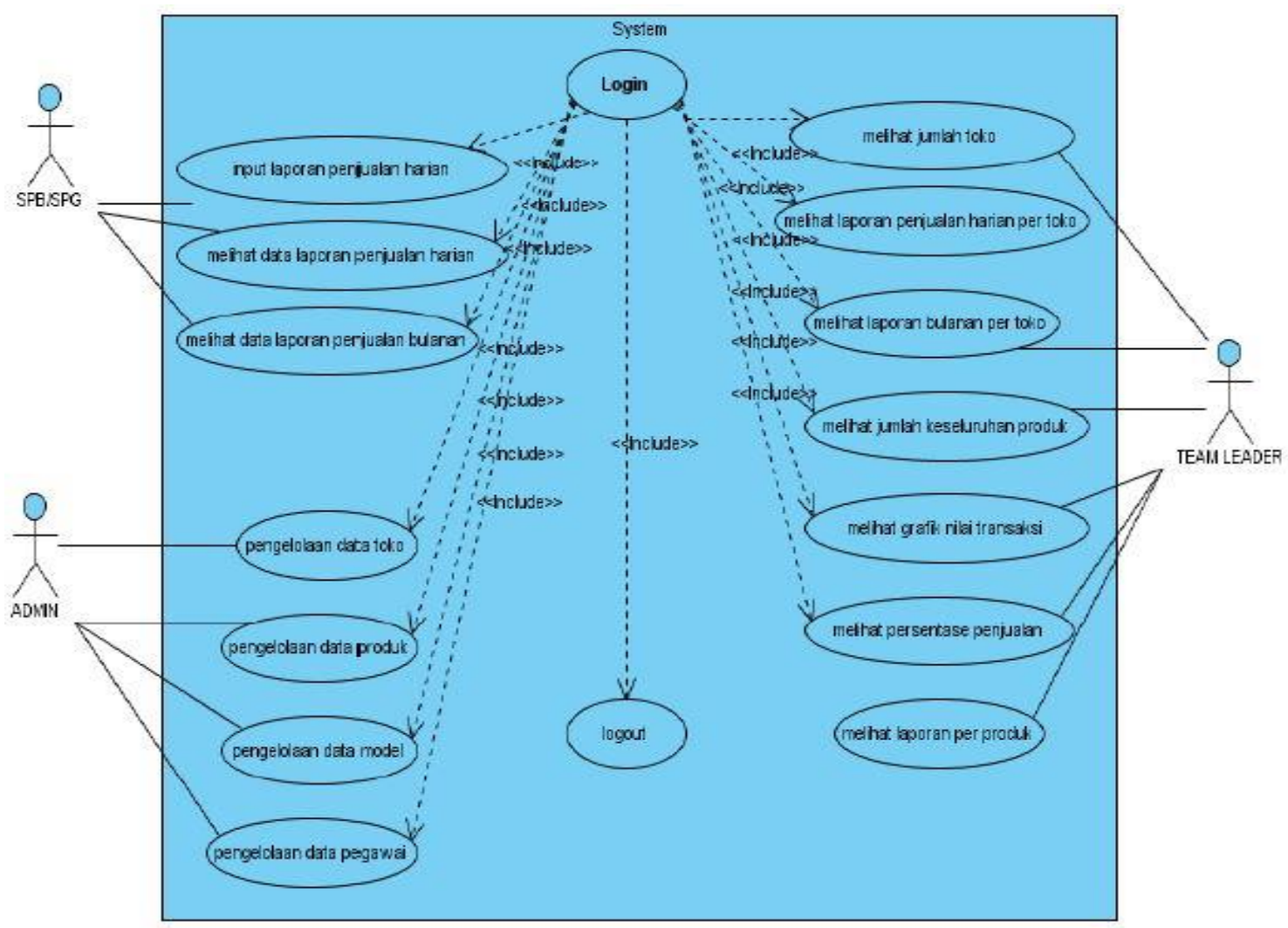

Gambar 6. Use case Diagram Sistem Informasi KPI metode OMAX berbasis WSA

Berdasarkan gambar 6. Use Case Diagram diatas terdiri dari :

1. Terdapat 1 sistem mencakup proses kegiatan yang berjalan

2. Terdapat 3 actor dalam proses kegiatan yang berjalan, yaitu Spg/Spb, Team Leader, Admin

3. 15 use case kegiatan oleh actor

\section{IMPLEMENTASI}

Sistem Informasi Key Performance Indicator metode OMAX berbasis Web Aplication System yang telah selesai dibangun dan dirancang nantinya akan diimplementasikan sebagai sarana informasi dan monitoring target penjualan dan performa indikator sales yang nantinya akan menjadi kunci indikator Manajemen dan Team Leader dalam menentukan perpanjangan kontrak kerja. Berikut adalah Sistem Informasi Key Performance Indicator metode OMAX berbasis Web Aplication System yang diimplementasikan di PT.Winn Appliance : 


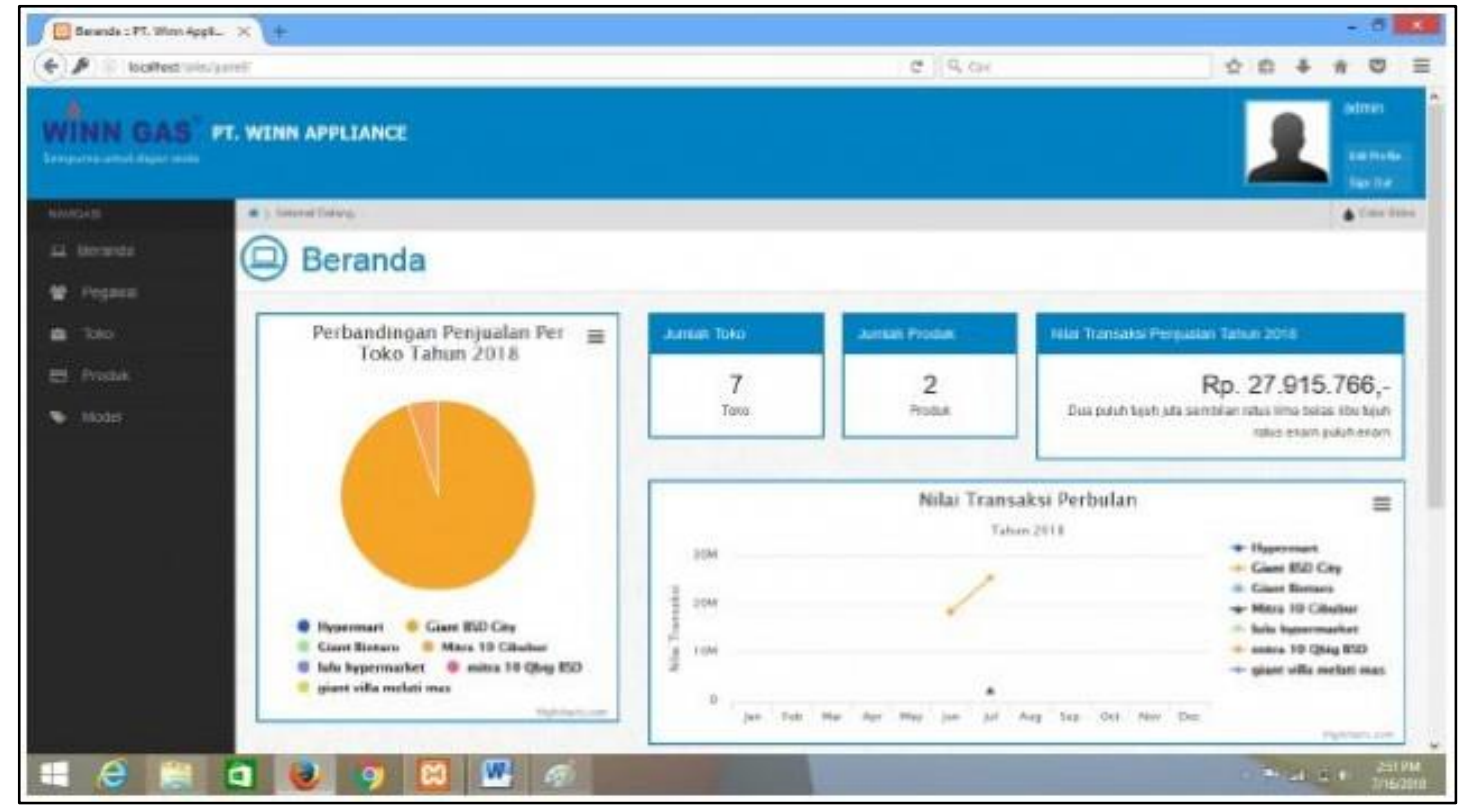

Gambar 7. Dashboard Key Performance Indicator

Pada gambar 7. merupakan sebuah halaman homepage pada Sistem Informasi Key Performance Indicator metode OMAX berbasis Web Aplication System,dimana ketika Team Leader membuka dan Login akan masuk ke halaman yang berformat dashboard Key Performance Indicator, terdapat gambar grafik penjualan yang menentukan produktifitas kinerja penjualan sales marketing.

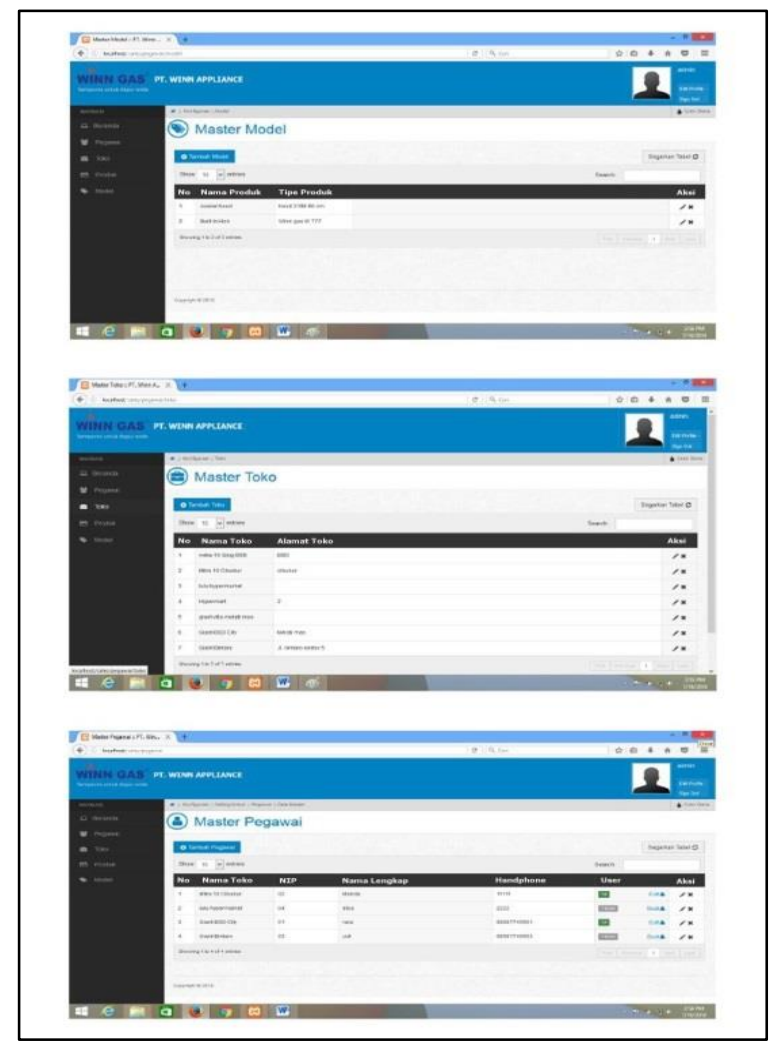

Gambar 8. Tiga Halaman Data Item 
Pada gambar 8 diatas terdapat tiga halaman data item yang diperlukan dalam pemrosesan data menjadi informasi. Adapun tiga halaman data item tersebut terdiri dari: Data master produk yang di jual, Data store setiap cabang dan Data karyawan di setiap store cabang.

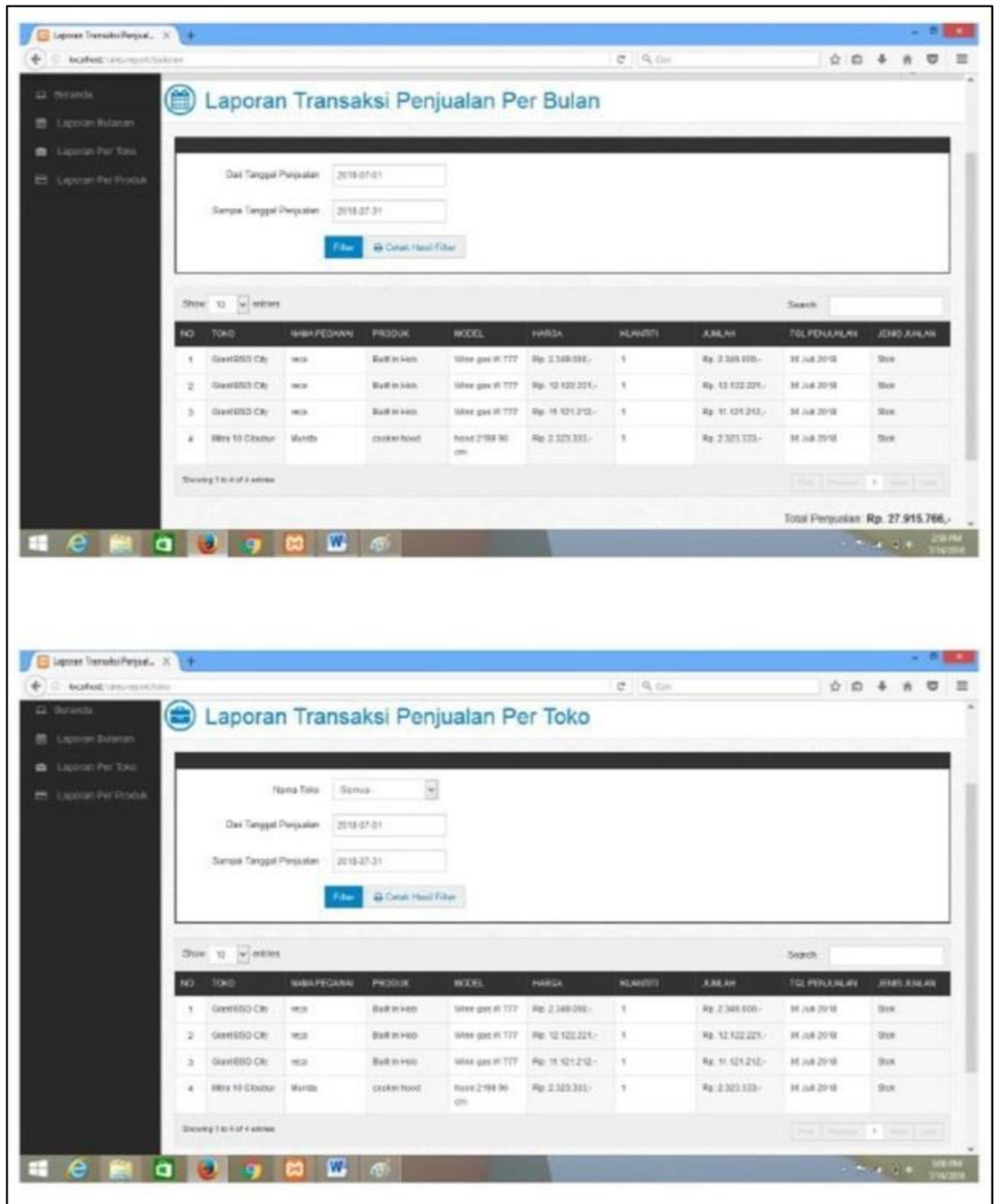

Gambar 9. Report Performance Penjualan Sales

Pada gambar 9. diatas terdapat dua halaman Report Transaksi Penjualan setiap karyawan dimasing masing store. Adapun dua halaman tersebut terdiri dari : Menu Laporan Per-bulan dan Menu Laporan Per-store, menu tersebut dapat menjadi satu faktor dimana nantinya manajemen dapat menentukan sales yg paling produktif dan tidak produktif. 


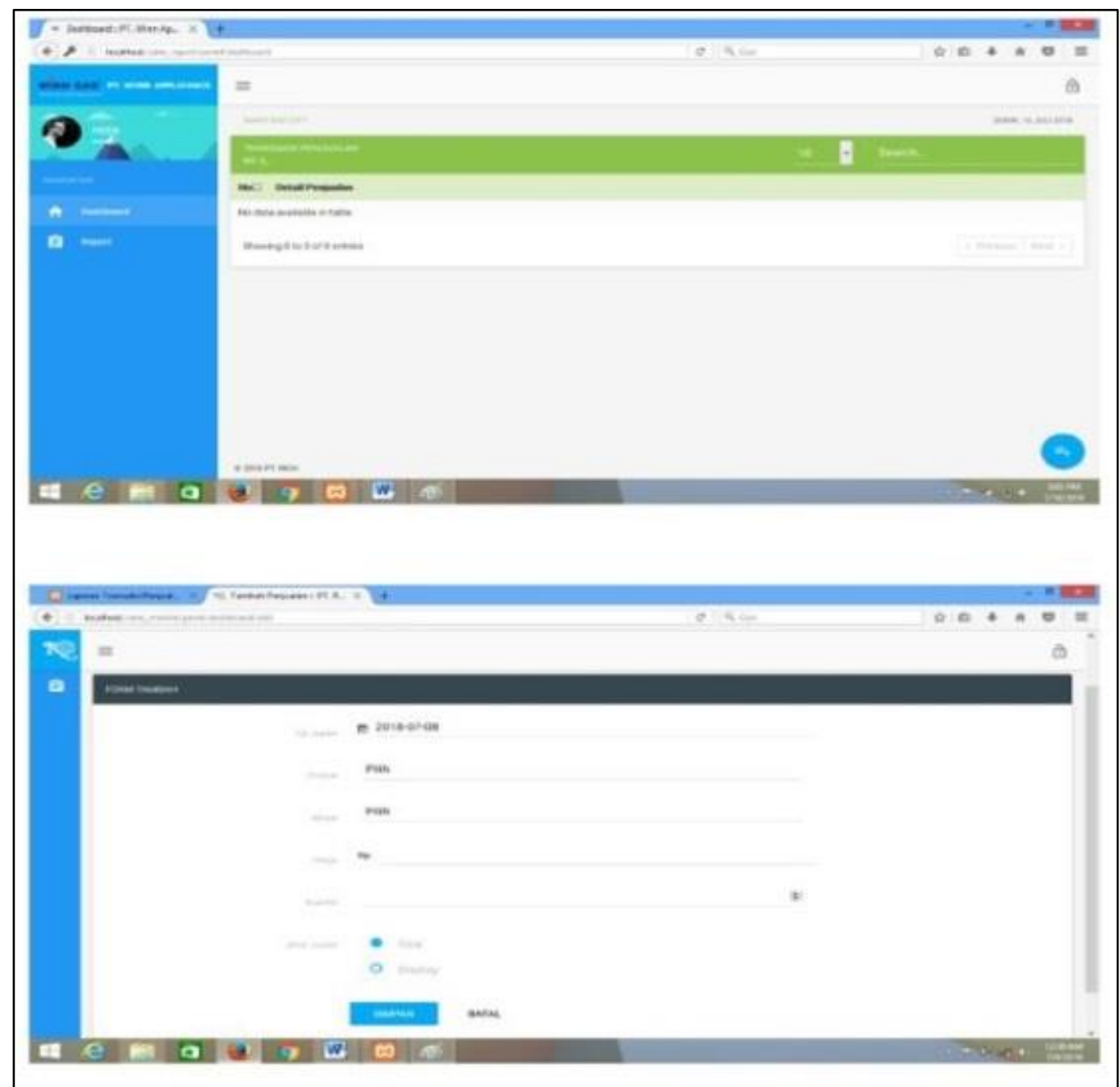

Gambar 10. Sales Menu Input Penjualan

Pada gambar 10. diatas terdapat dua halaman User (sales penjualan) yang dalam hal ini menginput setiap laporan penjualan yang telah berhasil dijual kepada para pembeli. Adapun dua halaman tersebut terdiri dari Menu Add New Penjualan dan Menu Form Pengisian data Penjualan.

\section{Kesimpulan}

Sistem informasi untuk monitoring laporan data penjualan saat ini pada PT. Winn Appliance masih menggunakan sistem aplikasi berbasis office yakni Microsoft Excel dan media pesan singkat Whatsapp sebagai sarana media dalam memberikan pertukaran informasi laporan penjualan. Dengan adanya kendala dan masalah dalam pengolahan data laporan penjualan maka manajemen perusahaan menemui kesulitan dalam menentukan keputusan perpanjangan kontrak kerja. Oleh sebab itu untuk mengembangkan dan merancang suatu sistem yang baru dibutuhkan sebuah sistem informasi yang User Friendly dan mudah diakses oleh User / pengguna. Merujuk pada kesimpulan masalah diatas, maka diputuskan kepada PT. Winn Appliance untuk membangun sistem informasi Key Performance Indicator dengan menggunakan metode OMAX yang berbasis Web System Aplication dengan tujuan bahwa sebuah sistem yang berbasis Website ini sangatlah sederhana namun lengkap, mudah diakses, user friendly dan mudah dipelajari bagi para User yang nantinya akan terlibat dalam sistem ini. 


\section{Saran}

Disarankan agar aplikasi sistem informasi Key Performance Indicator Penjualan metode OMAX yang berbasis Web System Aplication yang telah dibuat ini dapat disempurnakan dan dikembangkan lebih lanjut agar penggunaannya dapat terus bermanfaat sesuai dengan kebutuhan dan perkembangan PT.Winn Appliance nantinya.

\section{Daftar Pustaka}

[1] Parmenter, D. (2014). Key Performance Indicators. Canada: John Willey \& Sons.

[2] Junaidi, J., Cholisoh, N., \& Hasanah, N. (2018). Rancang Bangun Sistem Manajemen Aset IT Untuk Pencatatan History Maintenance Sebagai Pendukung Keputusan. SENSI Journal, 4(2), 220-231.

[3] Cholisoh, N., Friandi, S., \& Wiliam, G. (2019). Faktor Pengaruh Lingkungan Kerja Dan Disiplin Kerja Terhadap Kontribusi Kinerja Karyawan Pada PT. Gapura Angkasa Bandara Soekarno-Hatta. CICES, 5(1), 44-63. Retrieved from http://ejournal.raharja.ac.id/index.php/cices/article/view/570.

[4] Putri Ayu Retno Sari, Azis Fathoni \& Maria Magdalena. (2018) Pengembangan Pengukuran Key Performance Indicator Dengan Menggunakan Metode Objective Matrix (OMAX) di PT. Surya Mas Agung cabang Semarang. ISSN : 2502-7689 Journal of Management Universitas Pandanaran.

[5] Satzinger, Jackson dan Burd (2015), "Methode Systems Analysis and Design in a Changing World" Hal 45.

[6] SZ Friandi et all. Penerapan Sistem Informasi Manajemen Perizinan Online (SIMPONIE) Berbasis Website Dengan Menggunakan CI Framework (Studi kasus Dinas Penanaman Modal dan PTSP Kota Tangerang Selatan)". Proceeding SNIA 2019 Vo.4 ISSN: 23392304Universitas Jenderal Achmad Yani.

[7] Rifai, D., Friandi, S.Z., \& Pratama, T.A. (2018). Rancangan Sistem Aplikasi Pembayaran SPP Berbasis Website Dengan Menggunakan Metode Framework Yii (Studi Kasus di SDS Mulya Asri Kab. Tangerang). ICIT Journal, 4 (1), 52-61.

[8] Wandanaya, A. B., Friandi, S. Z., \& Maulana, F. A. (2019). Aplikasi Sistem Pengolahan Data Nilai Siswa Berbasis Web Pada SMKN 1 Kota Tangerang. CERITA Journal, 5 (1), 14-25. 